\title{
CORRIGENDA
}

\section{Association between the FTO rs9939609 polymorphism and leptin in European adolescents: a possible link with energy balance control. The HELENA study}

I Labayen, JR Ruiz, FB Ortega, J Dallongeville, D Jiménez-Pavón, MJ Castillo, S De Henauw, M González-Gross, G Bueno, D Molnar, A Kafatos, LE Díaz, A Meirhaeghe and LA Moreno International Journal of Obesity (2011) 35, 882; doi:10.1038/ijo.2011.90

Correction to: International Journal of Obesity (2011) 35, 66-71; doi:10.1038/ijo.2010.219

The authors would like to apologise for this error.

Upon publication of this paper the authors noted the misspelling of one of the listed authors' names. J Dalongeville should read J Dallongeville.

\section{Meal size can be decreased in obese subjects through pharmacological acceleration of gastric emptying (The OBERYTH trial)}

S Torra, L Ilzarbe, JR Malagelada, M Negre, A Mestre-Fusco, S Aguadé-Bruix, E Florensa, P Suñé, B Gras, JJ Hernandez, R Casamitjana, M Andreu Garcia, F Bory Ros and S Delgado-Aros

International Journal of Obesity (2011) 35, 882; doi:10.1038/ijo.2010.248

Correction to: International Journal of Obesity (2011) 35, 829-837; doi:10.1038/ijo.2010.210; published online 12 October 2010

The authors of the above article noted an error in publication of this paper (AOP and in this issue) in the Methods section of the abstract, wherein the second sentence was incorrect.
The correct sentence is shown below:

Ad libitum caloric intake and postprandial gastrointestinal symptoms were evaluated using a validated nutrient drink test, simultaneously measuring gastric emptying by scintigraphy.

The authors would like to apologize for this error. 